\title{
CYSTIC LYMPHANGIOMA: AN ATYPICAL PRESENTATION
}

\author{
A. Ravikumar ${ }^{1}$, Prasanna Kumar $\mathrm{S}^{2}$, Somu L ${ }^{3}$, Nazrin Md Ismail ${ }^{4}$
}

\section{HOW TO CITE THIS ARTICLE:}

A. Ravikumar, Prasanna Kumar S, Somu L, Nazrin Md Ismail. “Cystic Lymphangioma: An Atypical Presentation". Journal of Evolution of Medical and Dental Sciences 2014; Vol. 3, Issue 05, February 03; Page: 1075-1080, DOI:10.14260/jemds/2014/1948

ABSTRACT: Cystic lymphangioma is a lymphatic malformation which usually occurs at the time of birth or in the first few months of life. Cystic lymphangioma presenting in adulthood is less common. We report a case of a $21 \mathrm{yr}$. old adult male who presented with a rapidly progressive cystic swelling in the right submandibular region for the past 5 months. Further investigations were suggestive of lymphangioma. Surgical excision was challenging and resulted in complete cure without any morbidity, there was no evidence of recurrence at 3 years of follow up. We review the literature along with the case report of cystic lymphangioma presenting in adults.

KEYWORDS: Lymphangioma, cystic lymphangioma, cystic hygroma, cervicofacial lymphangioma.

INTRODUCTION: 'Hygroma' in Greek means water containing tumor. Cystic Hygroma or Cystic lymphangioma is a congenital malformation of the lymphatic system. $50 \%$ of these malformations appear at birth and about $80 \%$ to $90 \%$ manifest by 2 year of life 1 . The initial presentation in adults is less common, only about 100 cases have been reported in literature ${ }^{2}$. Lymphangioma can occur anywhere in the body but most common site is the head and neck region ${ }^{3}$. No sex preponderance or side predilection has been reported ${ }^{1}$. Infection in the respiratory tract or the skin or trauma in the head and neck region is associated with the rapid growth or engorgement with lymph or blood resulting in rapid increase in size. Cervicofacial lymphangioma has been reported to spontaneously regress in size in upto $15 \%$ of patients. Malignant change of lymphangioma has not been reported.

CASE REPORT: 21 year old male presented to the OPD with history of a rapidly progressive swelling in the right submandibular region for the past 5 months. He noticed that the swelling was bigger on lying down. There was no history of trauma, fever, pain, tooth ache or difficulty in breathing or swallowing.

On examination a $5 \times 4.5 \mathrm{~cm}$, soft, cystic, non-tender, fluctuant, compressible diffuse swelling (fig.1) was seen in the right submandibular region and upper part of neck extending superiorly to ramus of mandible, inferiorly to thyroid notch, medially just crossing the midline and laterally deep to sternocleidomastoid. Swelling was not reducible did not move on deglutition or protrusion of tongue. There was no cough impulse and transillumination was negative. There was no visible swelling in the floor of mouth and on bidigital palpation submandibular gland was palpable along with the swelling. On auscultation there was no bruit.

All the baseline investigations were normal. FNAC from the swelling was inconclusive. CT neck with contrast revealed multiloculated cyst with smooth septa, which enhanced uniformly after contrast injection. (fig.2)

Excision of the mass under general anesthesia was performed through a horizontal skin crease incision placed just $3 \mathrm{~cm}$ below the ramus of mandible. The finger like multiloculated cyst (fig.3) was seen extending deep to the mylohyoid muscle up to the floor of mouth which was fully 


\section{CASE REPORT}

resected with blunt dissection. Anterior belly of digastric muscle was cut and the mass was completely removed in toto. Intra operative and post-operative period was uneventful. Post operatively Facial nerve function was intact.

HPE (fig.4) showed large cystic space lined by attenuated endothelial cells. The lumen shows proteinaceous material and blood in foci. In the surrounding stroma dense foamy macrophage collection admixed with neutrophils and lymphocytes surrounding amorphous proteinaceous material is seen which are pathognomonic features of cystic lymphangioma.

DISCUSSION: Cystic lymphangioma is a subgroup of lymphangioma. Redenbacher (1828) used the term 'ranula congenital' to initially describe this lesion ${ }^{1}$. Wernher (1843) first used the term cystic hygroma ${ }^{1}$. Koester (1872) suggested that cystic hygromas were derived from lymphatic tissue ${ }^{1}$. It is generally agreed that lymphangioma is a congenital malformation of the lymphatic system.

Lymphangiomas have been classified into three groups (Landing and Farber, 1956) ${ }^{4}$ :

1. Lymphangioma simplex - composed of thin walled capillary sized lymphatic channel.

2. Cavernous lymphangioma - composed of dilated lymphatic spaces often with a fibrous adventitia

3. Cystic lymphangioma (cystic hygroma) - composed of cysts varying in size from few millimetre to several centimetre in diameter.

Bill and Summer have argued that there is no clearcut dividing line for the above classification ${ }^{5}$.

The type of lymphangioma depends on the tissue of origin, for e.g. if in the tongue it is more likely to be a lymphangioma simplex and if in the neck it is most likely to be cystic variety.

A cystic hygroma is defined as a benign proliferation of lymphoid tissue, and is usually considered as a congenital lesion. There are many cases reported in children but only about 100 cases of lymphangioma have been reported in adults ${ }^{6-10}$.

Cases presenting in adults often follow trauma or precede an upper respiratory infection ${ }^{9}$. In our case the swelling started and rapidly progressed in an adult male without antecedent history of trauma. Most of these lesions present with a painless swelling in the neck which gradually increases in size. The swelling is usually soft, cystic, fluctuant and transilluminant. These patients are asymptomatic except for the swelling. Symptoms may be due to a rapid increase in size of the swelling and depending on the region of involvement. In the head and neck it usually can cause respiratory distress or difficulty in swallowing.

Cystic lymphangiomas are most commonly seen in the neck (posterior triangle- 75\%). They can also be seen in the axillary region (20\%), mediastinum (5\%), retro peritoneum, pelvis and chest wall. Of all types of lymphangioma, Cavernous lymphangioma are the most common, accounting for $40 \%$ of lesions, occurring mainly in the tongue and the submandibular region which is the second commonest site.

A differential diagnosis of lipoma, branchial cyst, thyroglossal duct cyst, thymic cyst or Castleman's lymphoma cystic treatoma, plunging ranula, pericardial cyst should be kept in mind when dealing with cystic lymphangioma.

Diagnosis is usually based on history and clinical examination. Ultrasound ${ }^{11}$ or CT scan ${ }^{12}$ with contrast is sufficient to clinch the diagnosis as in our case. Ultrasound shows a multiloculated cystic lesion with intervening septa, large lesions do not have definitive anatomical boundaries. MRI 


\section{CASE REPORT}

is valuable in delineating the extent of lesion which is seen as multiloculated high intensity signals in T2 weighed images.

Fine needle aspiration biopsy will show small and round lymphocytes with intermingling histiocytosis. Some authors have suggested the use of FNAC and cytodiagnosis to aid in confirmation of the lesion. However opinions vary and some have found this investigation less useful, in our case the FNAC was inconclusive.

Early intervention is required as they are known for their rapid increase in size over a short duration causing compression of the larynx, trachea, oesophagus and great vessels of neck. We successfully excised the lesion completely by external surgical approach without any morbidity and post operatively this patient has been followed up for 3 year with no evidence of recurrence (fig 5). These lesions are sometimes difficult to manage, difficult because they expand and thus tend to stretch the neurovascular structures which results in functional and cosmetic problems. Our patient sought relief for cosmetic reason rather than functional impairment which was corrected by surgery.

There is no report of consistent, successful management of lymphangioma. Various modality of treatment have been tried. In the study conducted by Smith et al 6 children were treated by injecting OK-432. Of them two children with macrocystic lymphangioma had complete response to treatment, whereas three patients with microcystic lymphangioma and one patient with venous malformation did not show any signs of response ${ }^{13}$. Takao Ikarashi et al have successfully treated cystic lymphangioma in two adult patients by injecting $0 \mathrm{~K}-432$ intralesionally ${ }^{14}$. Turner $\mathrm{C}$ and Gross $S$ have reported 50\% reduction in the mass following the use of intravenous cyclophosphamide in treatment of recurrent cervicofacial lymphangioma15. Orford et al have reported the use of sclerosing agents such as Belomycin and have reported that seven out of sixteen patients had complete response ${ }^{16}$. Castanon GAM et al have used fibrin glue and found it to be useful in management of lymphangioma ${ }^{17}$. At present, surgical excision has the best option for managing cervicofacial lymphangioma. The prognosis is good for surgically treated cases of cystic lymphangioma. Infection, local recurrences and fistula formation are few of the common complications faced after surgery.

CONCLUSION: Cystic lymphangioma in adults presents a diagnostic challenge because of its rarity in adults. Appropriate radiological imaging is necessary to locate the extent of disease for a complete surgical excision with a good prognosis. Since it's a compressible cystic swelling with a finger like extension into the deep tissue fascial plane which was firmly adherent over the adjacent vital structure, meticulous dissection was required to resect the mass completely.

\section{REFERENCES:}

1. McGill TJ, Mulliken JB. Vascular anomalies of the head and neck. In: Cummings CW, Friedrickson JM, Harker LA, et al, editors. Otolaryngology- head and neck surgery, vol 1. 2nd ed. St. Louis: Mosby; 1993. p. 333-46.

2. Redenbacher, E. A. H. De Ranula Sub Lingua, Speciali, Cum Casu Congenito. Lindauer, Monachii.

3. Serres MD, Sie KCY et al. Lymphatic malformations of the head and neck: proposal for staging. Arch Otolaryngol Head Neck Surg; 1995. 121(5):577-582.

4. Landing, B. H., and Farber, S. Tumours of the cardiovascular system. Atlas of Tumour Pathology. Sect. III Fasc. 7. Armed Forces Institute of Pathology, Washington D.C.1956. 
5. Bill, A. H., and Sumner, D. S. A unified concept of lymphangioma and cystic hygroma. Surgery, Gynecology and Obstetrics, 1965; 120, 79.

6. Goodman P, Yeung CS, Batsakis JG. Retropharyngeal lymphangioma presenting in an adult. Otolaryngol Head Neck Surg. 1990; 103(3):476-479.

7. Schefter RP, Olsen KD, Gaffey TA. Cervical lymphangioma in the adult. Otolaryngol Head Neck Surg. 1985; 93(1):65-69.

8. Muñoz Herrera A, Pe'rez Plasencia D, Go'mez Benito M, Santa Cruz Ruiz S, Flores Corral T, Aguirre Garcı'a F. Cervical lymphangioma in adults- Description of 2 cases. Ann Otolaryngol Chir Cervicofac. 1998; 115(5):299-302.

9. Aneeshkumar MK, Kale S, Kabbani M, David VC. Cystic lymphangioma in adults: can trauma be the trigger? J Laryngol Otol. 1992; 106:566-568.

10. Wiggs WJ and Sismanis A. Cystic hygroma in the adult: two case reports. Otolaryngology and Head and Neck surgery. February 1994; 239-241.

11. Mandel L. Parotid area lymphangiomas in an adult: case report. J Oral Maxillofac Surg. 2004; 62(10):1320-1323.

12. Woods D, Young JE, Filice R, Dobranowski J. Late-onset cystic hygromas: the role of CT. Can Assoc Radiol J 1989; 40:159-161.

13. Smith RJ et al. OK-432 therapy for lymphangiomas. Archives. Otolaryngology and Head and Neck Surgery. Nov 1996: 122(11); 1195-1199.

14. Takao Ikarashi, Kazutoshi Inamura, Yo Kimura. Cystic Lymphangioma and Plunging Ranula Treated by OK-432 Therapy: A Report of Two Cases Acta Otolaryngol (Stockh) 1994; Suppl 51 1: 196-199.

15. Turner C, Gross S. Treatment of recurrent suprahyoid cervicofacial lymphangioma with intravenous cyclophosphamide. American Journal of Pediatric Hematology-Oncology.1994: 16(4); 325-328.

16. Orford J et al. Bleomycin therapy for cystic hygroma. Journal of Paediatric Surgery. 1995: $30(9) ; 1282-1287$.

17. Castanon GAM et al. Cystic lymphangioma: treatment with adhesive fibrin tissue. Follow up study. Cirugia Pediatrica.1996: 9(1); 36-39.

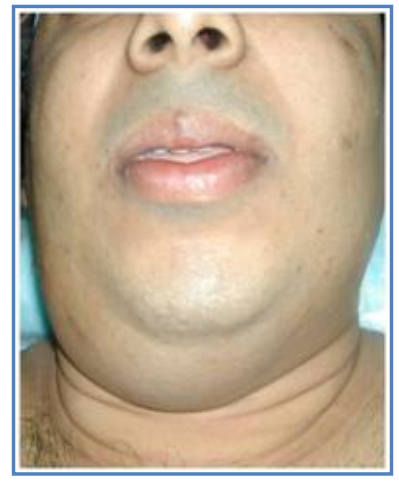

Frontal view of the patient showing a $1-5 \times 4.5 \mathrm{~cm}$, soft, cystic, non tender, fluctuant, compressible diffuse swelling seen in the right submandibular region.

\section{Fig. 1}




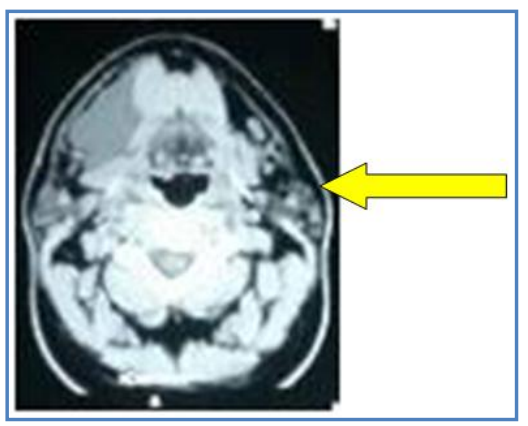

Fig. 2

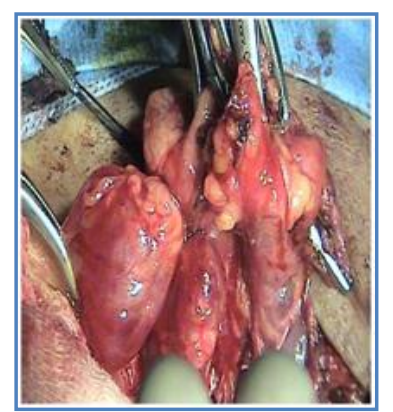

Fig. 3

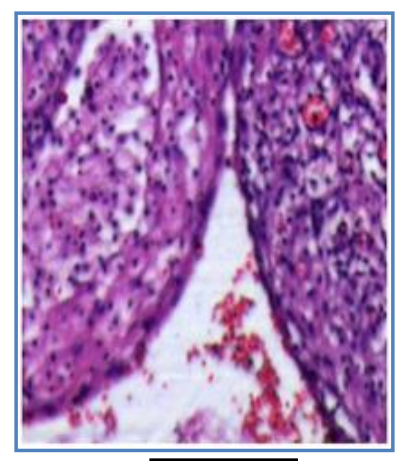

Fig. 4

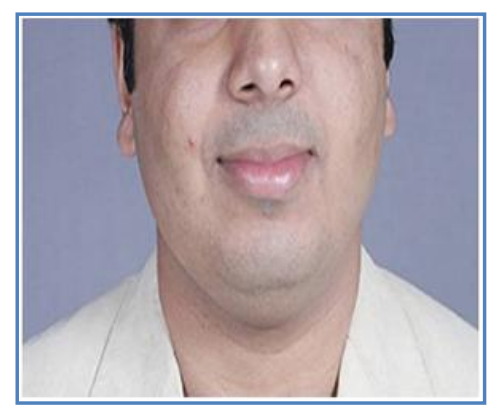

Intra operative picture, showing finger like multiloculated cyst seen extending deep to the mylohyoid muscle up to the floor of mouth. multiloculated cyst with smooth septa in the submandibular region.

Histopathology slide x200 showing large cystic spaces lined by attenuated endothelial cells. In the surrounding stroma dense foamy macrophage admixed with neutrophils and lymphocytes surrounding amorphous proteinaceous material is seen.

\section{Fig. 5}




\section{AUTHORS:}

1. A. Ravikumar

2. Prasanna Kumar S.

3. Somu L.

4. Nazrin Md Ismail

\section{PARTICULARS OF CONTRIBUTORS:}

1. Professor, Department of ENT, Sri Ramachandra Medical College and RI, Porur, Chennai.

2. Associate Professor, Department of ENT, Sri Ramachandra Medical College and RI, Porur, Chennai.

3. Professor, Department of ENT, Sri Ramachandra Medical College and RI, Porur, Chennai.
4. Senior Resident, Department of ENT, Sri Ramachandra Medical College and RI, Porur, Chennai.

\section{NAME ADDRESS EMAIL ID OF THE CORRESPONDING AUTHOR:}

Dr. Prasanna Kumar S., Dept of ENT, Head and Neck Surgery, Sri Ramacnandra medical college and RI, Porur, Chennai.

E-mail: sprasannakumar10@gmail.com

Date of Submission: 23/12/2013.

Date of Peer Review: 24/12/2013.

Date of Acceptance: 18/12/2013.

Date of Publishing: 28/01/2014 